\title{
Ocean-atmosphere-wave characterisation of a wind jet (Ebro shelf, NW Mediterranean Sea)
}

\author{
Manel Grifoll $^{1}$, Jorge Navarro ${ }^{2}$, Elena Pallares ${ }^{1}$, Laura Ràfols ${ }^{1,3}$, Manuel Espino ${ }^{1}$, and Ana Palomares ${ }^{2}$ \\ ${ }^{1}$ LIM/UPC (BarcelonaTech), Barcelona, Spain \\ ${ }^{2}$ CIEMAT, Madrid, Spain \\ ${ }^{3}$ Meteocat, Barcelona, Spain \\ Correspondence to: Manel Grifoll (manel.grifoll@upc.edu)
}

Received: 13 January 2016 - Published in Nonlin. Processes Geophys. Discuss.: 25 January 2016

Revised: 3 May 2016 - Accepted: 23 May 2016 - Published: 15 June 2016

\begin{abstract}
In this contribution the wind jet dynamics in the northern margin of the Ebro River shelf (NW Mediterranean Sea) are investigated using coupled numerical models. The study area is characterised by persistent and energetic offshore winds during autumn and winter. During these seasons, a seaward wind jet usually develops in a $\sim 50 \mathrm{~km}$ wide band offshore. The COAWST (Coupled Ocean-Atmosphere-Wave-Sediment Transport) modelling system was implemented in the region with a set of downscaling meshes to obtain high-resolution meteooceanographic outputs. Wind, waves and water currents were compared with in situ observations and remote-sensingderived products with an acceptable level of agreement. Focused on an intense offshore wind event, the modelled wind jet appears in a limited area offshore with strong spatial variability. The wave pattern during the wind jet is characterised by the development of bimodal directional spectra, and the ocean circulation tends to present well-defined twolayer flow in the shallower region (i.e. inner shelf). The outer shelf tends to be dominated by mesoscale dynamics such as the slope current. Due to the limited fetch length, ocean surface roughness considering sea state (wave-atmosphere coupling) modifies to a small extent the wind and significant wave height under severe cross-shelf wind events. However, the coupling effect in the wind resource assessment may be relevant due to the cubic relation between the wind intensity and power.
\end{abstract}

\section{Introduction}

Coastal areas are often characterised by highly variable and heterogeneous wind, wave and current conditions, which make the numerical prediction of the meteo-oceanographic processes difficult. For instance, wind jets induced by orographic effects present strong spatial wind field variability due to the orographic characteristics (e.g. Shimada and Kawamura, 2006; Zhai and Bower, 2013). Due to the persistence in wind intensity and direction, these regions are preferential sites for the installation of offshore wind farms (Nunalee and Basu, 2014). In the case of coastal regions, the resultant offshore winds decisively influence the exchange of water mass and material along the shelf/slope (Jordà, 2005; Barton et al., 2009). Despite the relatively limited fetch in the wind jet region, the wave height can be relevant, interacting with bimodal features (Shimada and Kawamura, 2006). In this sense, several contributions have highlighted the influence of variable wind conditions in relatively smallscale areas (such as wind jet), influencing wind-wave generation (Shimada and Kawamura, 2006; Bolaños-Sanchez et al., 2007; Alomar et al., 2014) or modifying ocean circulation patterns (Csanady, 1980; Zhai and Bower, 2013; Schaeffer et al., 2011; Klaić et al., 2011).

In coastal zones the air-sea momentum transfer presents a high complexity due to the dependence of wind intensity on ocean surface roughness. The relevance of the atmospheric bottom roughness increasing due to waves has been investigated in recent years (Janssen, 1989; Janssen and Viterbo, 1996; Lionello et al., 1998; Taylor and Yelland, 2001; Oost et al., 2002; Drennan et al., 2003). In this sense, advanced computational tools allowed for the feedback of meteo- 

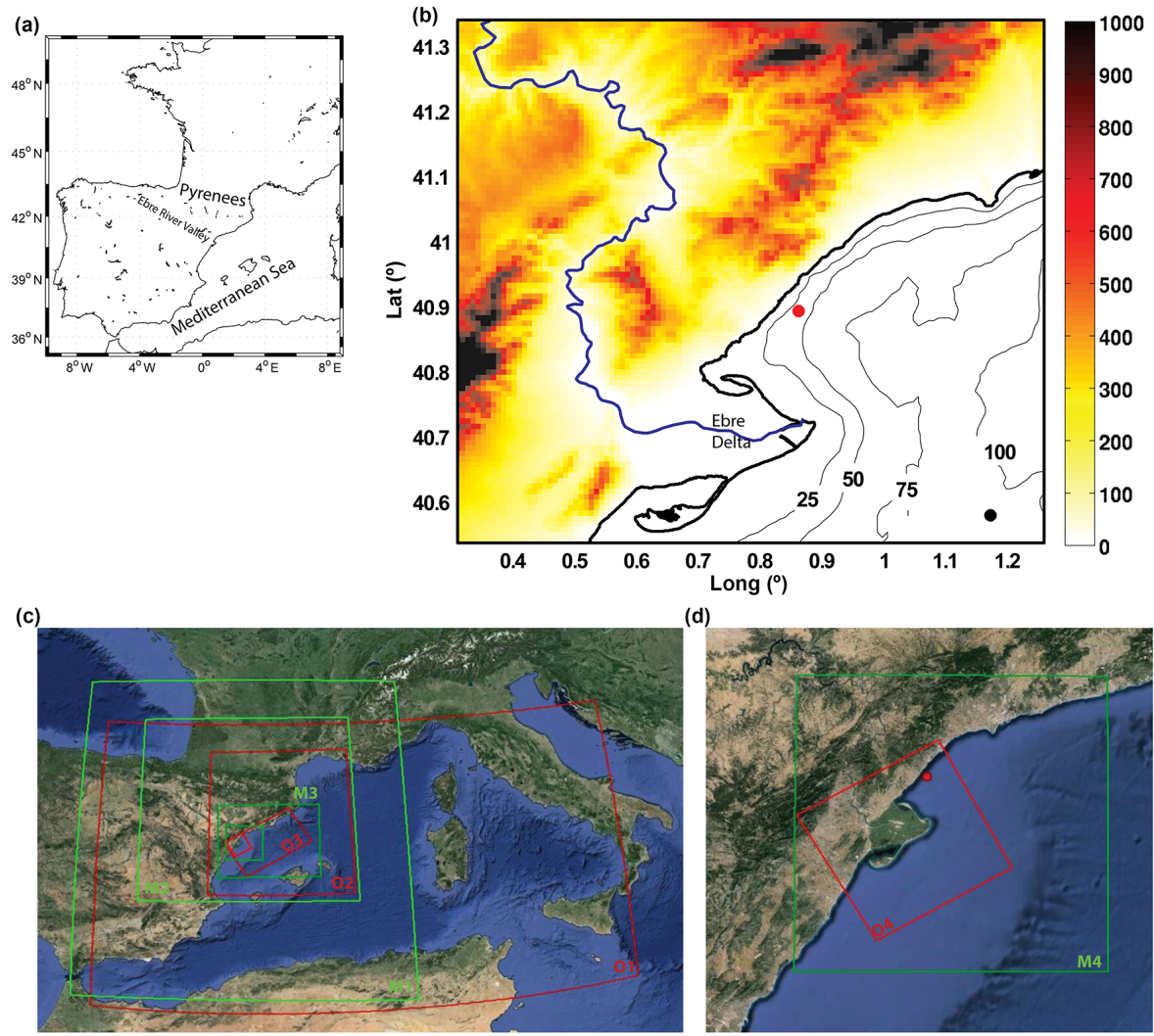

Figure 1. Localisation map (a) and orography (coloured map) and bathymetry of the study area (b). The bathymetry lines are shown every $25 \mathrm{~m}$. The geographical position where the observational buoy was moored is shown with a red circle. The control point used in the analysis is shown with a black circle. (c, d) Geographical domains for the meteorological model (in green) and the wave and the water circulation model (in red). The mesh notation is also shown (its resolution is detailed in Table 1).

oceanographic momentum and heat transfer to be addressed numerically (Warner et al., 2010; Zambon et al., 2014). Warner et al. (2010) developed a fully coupled numerical system (COAWST: Coupled Ocean-Atmosphere-WaveSediment Transport) to investigate the impact of storms on coastal systems. Using COAWST, Olabarrieta et al. (2012) and Renault et al. (2012) proved numerically that the waveinduced ocean surface roughness is a key parameter in the air-sea momentum transfer. Under severe storm conditions (hurricanes and cyclones), this parameter influences the spatial and temporal evolution of the meteo-oceanographic variables. Other recent examples that use a fully numerical model to investigate the air-sea interaction and its effect on oceanographic processes are found in Nelson and He (2012) and Drews (2013).

The case of the Ebro River shelf (NW Mediterranean Sea; see Fig. 1) is characterised by a strong, dry and usually cold wind that blows from the north-west through the Ebro valley. The westerly wind, greatly affected by the orography, is channelised into a limited band, forming a wind jet (Jansà, 1985; Spanish Ministry of Energy, 2014). The synoptic situation is related to an anticyclone in the Bay of Biscay and a low-pressure area in the Mediterranean Sea (Riosalido et al., 1986; Font, 1990; Martín-Vide, and Olcina, 2001; Cerralbo et al., 2015). Offshore wind is more usual and intense during autumn and winter, when larger atmospheric pressure gradients take place and cause stronger winds with an advection of cold air, but a small atmospheric pressure difference along the Ebro valley is sufficient to initiate wind during any season (Riosalido et al., 1986; Cerralbo et al., 2015).

The objective of this contribution is to describe the meteooceanographic processes associated with a wind jet developing at the northern margin of the Ebro River shelf. This work provides insight into wind jets in an orographically complex region, such as the Ebro delta shelf, describing the main wind, wave and current patterns and the feedback relative to the air-sea momentum transfer in terms of waveinduced ocean surface roughness. After the introduction (Sect. 1), in Sect. 2 (Methods) we describe the study area, the COAWST model implementation and the wind jet event selected to investigate in detail the meteo-oceanographic dynamics. Then, in Results (Sect. 3) we show the most relevant meteo-oceanographic processes observed and a detailed skill assessment of the fields modelled, comparing them with a set of available data (i.e. in situ observations and remotesensing products). Also, the feedback in the air-sea momen- 
tum transfer in terms of wave-induced ocean surface roughness is investigated with a set of coupled simulations testing different air-sea momentum transfer formulations. Afterwards, we discuss (Sect. 4) the relevance and particularities of the dynamics of the wind jet area in terms of waves, winds and currents, comparing with previous investigations. The implications of the wind-wave coupling in terms of the wind resource assessment are highlighted. We close with the Conclusions (Sect. 5).

\section{Methods}

\subsection{Study area and observations}

The meteorological patterns over the NW Mediterranean Sea exhibit sharp gradients associated with the topographic control on synoptic fluxes (Jansà, 1985; Martín-Vide and Olcina, 2001). Regional wind analysis reveals strong and persistent cross-shelf winds. A channelisation effect associated with the Ebro valley triggers north-westerly winds (called Mestral: Catalan for Mistral wind), resulting in a wind jet. Previous studies based on long-term wind measurements in the proximity of the region showed that winds have a persistent seasonal pattern (Font, 1990; Cerralbo et al., 2015; Grifoll et al., 2015). During winter and autumn, a dominant northwesterly component caused by wind channelisation was observed. For instance, recent wind measurements revealed that cross-shelf winds were observed more than $60 \%$ of the time during these seasons (Grifoll et al., 2015). In this period, the energy is concentrated in the low frequencies associated with synoptic scales (periods of 2-5 days, corresponding with the passage of weather systems). However, the warmer period (spring and summer) is characterised by high variability with a dominance of south-westerly winds. This means that during spring and summer the relative contribution of the daily components (breezes) to the variability increases with respect to the synoptic winds (Font, 1990; Cerralbo et al., 2015). The warmer seasons are less energetic than the cold seasons in terms of wind intensity.

The Ebro River delta is located immediately to the south of the wind jet region, and the average annual river discharge ranges between 300 and $600 \mathrm{~m}^{3} \mathrm{~s}^{-1}$. The curvature of the bay partially shelters it from southerly waves. Regional wave climate in this area is characterised by the south-eastern and eastern sectors, the latter being the most energetic due to having the largest fetches (Bolaños-Sanchez et al., 2007).

Oceanographic investigations in the Ebro River region were focused primarily on the outer shelf and slope dynamics of the southern margin (Font, 1990; Palanques et al., 2002; Salat et al., 2002; Jordà, 2005) with relevant eddy activity (Redondo et al., 2013). The circulation in these regions is dominated by the inertial band, with a relevant signal of the slope current associated with the regional northern current northern or Liguro-Provençal-Catalan current (Jordà, 2005).
Observational analyses have revealed that the inner and midshelf (less than $50 \mathrm{~m}$ water depth) dynamics in the Ebro shelf are characterised by a strong influence of the frictional component of the flow (Jordà, 2005; Grifoll et al., 2015). Furthermore, the regional response to wind jets is not clear due to the complex bathymetry and the spatial variability of the wind jet. Durand et al. (2002) and Mestres et al. (2003) showed that the effects of the salinity river plume are important only near the river mouth (of the order of $10 \mathrm{~km}$ offshore from the river mouth).

As a part of large effort to collect physical data and implement numerical tools for the assessment of offshore wind energy potential, a buoy was moored in the northern margin of the Ebro shelf where the wind jet develops (see Fig. 1). The buoy was moored $3.1 \mathrm{~km}$ from the coast at $43.5 \mathrm{~m}$ bottom depth, measuring wind, waves and water currents for 1 year. A TRIAXYS directional wave sensor mounted on the moored buoy was used to record statistical wave spectra parameters. Wind speed and direction were measured at $4 \mathrm{~m}$ height every $10 \mathrm{~min}$ using an ultrasonic wind sensor (Gill Instruments) for 1 year (November 2011 to November 2012). Water currents were measured with a SonTek acoustic Doppler current profiler (ADCP) at $500 \mathrm{kHz}$ every hour using 20 vertical layers (layer depth was $2 \mathrm{~m}$ ). The mooring period covered more than 1 year (from November 2011 to December 2012).

Additionally, satellite-measured winds were used for the numerical model validation. Sea wind intensity and direction were obtained from the National Climatic Data Center (NCDC-NOAA; http://www.ncdc.noaa.gov/oa/rsad/ air-sea/seawinds.html). This product is the result of a spatial and temporal interpolation of the data received from the different satellites passing through the study area during a time interval, and it has $6 \mathrm{~h}$ time resolution and $0.25^{\circ}$ spatial resolution.

\subsection{Numerical model and meshes}

The COAWST modelling system (Warner et al., 2010) was used in this study. COAWST relies on the three-dimensional (3-D) ocean modelling ROMS (Regional Ocean Modeling System; see Haidvogel et al., 2000), the phase-averaged wave model SWAN (Simulating WAaves Nearshore; see Booij et al., 1999), the non-hydrostatic meteorological model WRF (Weather Research and Forecasting; Skamarock et al., 2005) and the sediment transport module CSTMS (Community Sediment Transport Modeling System; Warner et al., 2008). The ocean model ROMS is a freesurface, terrain-following numerical model, which resolves the 3-D Reynolds-averaged Navier-Stokes (RANS) equations using hydrostatic and Boussinesq approximations. The WRF model (advanced research WRF version) is a nonhydrostatic, quasi-compressible atmospheric model with a variety of physical parameterisations of sub-grid-scale processes for predicting meso- and microscales of motion. The 
SWAN model solves the wave action balance equation simulating wind generation and propagation in deep and coastal waters. The modelling system COAWST includes the coupler Model Coupling Toolkit (MCT; Jacob et al., 2005) for the transmission and transformation of the physical variables using a parallel computing approach. The COAWST system also allows for the exchange of data fields on different grids using the Spherical Remapping Interpolation Package (SCRIP; Jones, 1999) to compute the interpolation weights.

The largest wave domain (mesh O1) covers the western Mediterranean Sea, which is considered large enough to capture the wave generation in the study area. The SWAN model implementation used amends the underestimation in the wave growth rates reported by Alomar et al. (2014) and Rogers et al. (2003) in a low- and medium-frequency energy spectrum. The measure adopted was introduced by Pallares et al. (2014) and consists in modifying the whitecapping dissipation term (see Appendix A1).

The largest water circulation domain (mesh O3) is nested into the daily MyOcean-MEDSEA product (Tonani et al., 2009 ), with a horizontal resolution of $1 / 16^{\circ} \times 1 / 16^{\circ}$ and 72 unevenly spaced vertical levels, in order to provide suitable boundary conditions for the oceanographic variables in terms of water velocity, sea level, temperature and salinity. The 3-D ocean model implementation (ROMS) includes a generic length-scale turbulent-mixing scheme (Umlauf and Burchard, 2003), with coefficients selected to parameterise the $k$-epsilon scheme (Rodi, 1987) and fourth-order biharmonic Laplacian viscosity and mixing terms on geopotential surfaces for velocity and tracers, respectively, both with constant coefficients of $0.5 \mathrm{~m}^{4} \mathrm{~s}^{-2}$. The bottom boundary layer was parameterised using a log profile with bottom roughness equal to $0.005 \mathrm{~m}$. The time interval for data exchange between the models is $600 \mathrm{~s}$.

The atmospheric model is nested into the ECMWF (European Centre for Medium-Range Weather Forecasts) ERAInterim reanalysis product considering four downscaling meshes - M1, M2, M3 and M4 with resolutions of 27, 9, 3 and $1 \mathrm{~km}$, respectively - to obtain suitable grid resolution for the complex orography of the region (see Fig. 1). The WRF implementation uses a Mellor-Yamada-NakanishiNiino (MYNN) level 2.5 planetary boundary layer scheme. The nesting strategy consists of a set of different downscaling meshes (Fig. 1c and Table 1). The ocean-atmosphericwave online coupling was implemented in the finer domain (mesh $\mathrm{O} 4$ for the wave and circulation model, and mesh M4 for the meteorological model) where the scale of the coupling process due to cross-shelf winds may be more evident in the results. In this case, air-sea coupled effects are included considering the Taylor and Yelland formulation (Taylor and Yelland, 2001), for the ocean surface roughness modification due to the wave effect, and vortex force for the wave effects on currents (Olabarrieta et al., 2012).
Table 1. Resolution (in $\mathrm{km}$ ) of the different domains/meshes used in the nested system as a function of each numerical model and regional scale covered. In parentheses the mesh name in Fig. 1 is shown.

\begin{tabular}{llccl}
\hline Model & $\begin{array}{l}\text { NW } \\
\text { Mediterranean }\end{array}$ & $\begin{array}{c}\text { Catalan- } \\
\text { Balearic } \\
\text { Sea }\end{array}$ & $\begin{array}{c}\text { Catalan } \\
\text { coast }\end{array}$ & $\begin{array}{l}\text { Ebro } \\
\text { delta }\end{array}$ \\
\hline WRF & $27(\mathrm{M} 1)$ & $9(\mathrm{M} 2)$ & $3(\mathrm{M} 3)$ & $1(\mathrm{M} 4)$ \\
SWAN & $9(\mathrm{O} 1)$ & $3(\mathrm{O} 2)$ & $1(\mathrm{O} 3)$ & $1 / 4(\mathrm{O} 4)$ \\
ROMS & - & - & $1(\mathrm{O} 3)$ & $1 / 4(\mathrm{O} 4)$ \\
\hline
\end{tabular}

\subsection{Episode description and numerical sensitivity test}

As we noted in the introduction, the air-sea momentum transfer presents high complexity due to the relation of wave characteristics and the ocean surface roughness, which in turn affect the wind field. In order to investigate the air-sea momentum transfer in the wind jet, a set of simulations have been designed applying different air-sea momentum transfer formulations included in the COAWST modelling system. The sensitivity tests pursue an evaluation of the "coupling" effects on two principal variables involved in the air-sea momentum transfer: wind intensity $(W)$ and significant wave height $\left(H_{\mathrm{s}}\right)$. In this sense three different formulations have been tested (see Appendix A2), which consider the modification of the atmospheric bottom roughness due to the waves. In consequence, we compare directly the "coupled" results with an "uncoupled" simulation where the bottom roughness length is only a function of the wind stress. The sensitivity tests are as follows: CHK for the simulation considering the bottom roughness as a function of the wind stress (uncoupled with the wave sea state) using the Charnock coefficient equal to 0.016 , T-Y simulation considering the Taylor and Yelland formulation (Taylor and Yelland, 2001), DRE using the Drennan formulation proposed by Drennan et al. (2003) and OOST simulation considering the formulation introduced by Oost et al. (2002). Two numerical points are chosen to compare the results for the sensitivity test simulations. One point is near the buoy's moored position (where the numerical results are also compared with the measurements). The second point is located $30 \mathrm{~km}$ offshore of the measurement point (see control point in Fig. 1). This point has been chosen in order to capture the wave growth due to cross-shelf winds and evaluate properly the coupling-uncoupling differences.

We select a cross-shelf wind event in order to characterise in detail the meteo-oceanographic dynamics of the wind jet. The episode selected for the sensitivity tests lasted from 19 to 23 March 2012. The synoptic situation during the selected episode corresponds to a typical offshore wind event induced by atmospheric pressure differences (see Fig. 2). A high-atmospheric-pressure area is centred over the North Atlantic Ocean, with the anticyclonic edge affecting part of the Iberian Peninsula. The low pressure is located in the cen- 


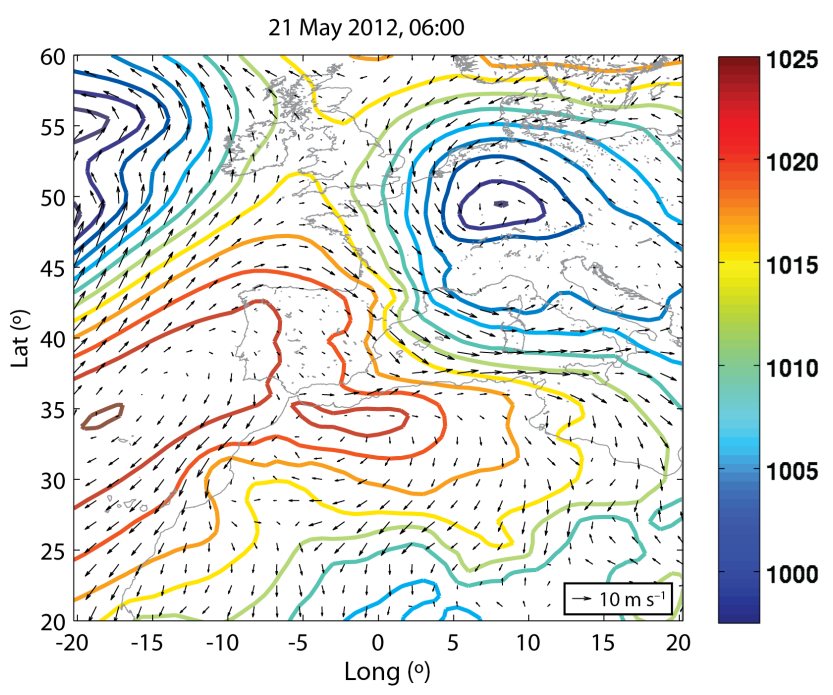

Figure 2. Regional chart of the mean sea level pressure (hPa) during 21 May at 06:00 UTC (representative of the synoptic situation during the selected cross-shelf wind event). Data source: ERA-Interim global reanalysis from ECMWF. Arrows represent the wind field.

tre of Europe. In this situation the cross-shore winds in the Ebro delta zone are intensified. The sequence of wind field modelled in the Catalan coast mesh during the wind jet period is characterised by a rise of wind intensity during the 20 and 21 May, leading to a wind jet in the northern margin of the Ebro delta (see daily-averaged wind intensity in Fig. 3). Then, the cross-shore winds remain strong during 22 May, decreasing during the 23 May 2012.

\section{Results}

\subsection{Description of meteo-oceanographic processes and skill assessment}

The skill assessment of the model is carried out for different meshes in function with the spatial coverage of the observations. Modelled winds during the simulation period reproduce the main wind directions previously reported in the study area. Offshore wind prevails throughout the year, intercalated with southerly winds during spring and summer (i.e. sea breeze). The adjustment of the wind time series into a Weibull distribution is used to evaluate the statistical inter-comparison between wind observations (measured from the buoy and satellite) and the $3 \mathrm{~km}$ WRF model results (mesh M3). Blended Sea Winds were used from the NOAA/NCDC SeaWinds project which contain 6-hourly globally gridded, high-resolution ocean surface vector winds and wind stresses on a global $0.25^{\circ}$ grid. Figure 4 shows the Weibull distributions considering the wind intensity time series. Also the global model (i.e. ECMWF) used for WRF model downscaling is included. The results show that for high and medium range wind speeds $\left(>2.5 \mathrm{~m} \mathrm{~s}^{-1}\right)$, the nu-
Table 2. Statistics for the comparison between buoy measurements and model outputs. $W$ is the wind intensity (in $\mathrm{m} \mathrm{s}^{-1}$ ), $H_{\mathrm{s}}$ is the significant waves height (in $\mathrm{m}$ ), $\mathrm{Tm}_{01}$ is the mean wave period (in $\mathrm{s}$ ) and $U$ is the depth-averaged along-shelf current (in $\mathrm{cm} \mathrm{s}^{-1}$; positive north-eastward). The statistical parameters are the root mean square error (RMSE), the bias and the correlation coefficient $(R)$.

\begin{tabular}{lrrrrr}
\hline & \multicolumn{2}{c}{ Observed } & RMSE & Bias & $R$ \\
\cline { 2 - 3 } & Mean & SD & & & \\
\hline$W$ & 6.59 & 4.52 & 2.70 & 0.68 & 0.79 \\
$H_{\mathrm{S}}$ & 0.62 & 0.42 & 0.29 & 0.09 & 0.76 \\
$\mathrm{Tm}_{01}$ & 3.48 & 0.92 & 3.57 & -1.14 & 0.57 \\
$U$ & -4.60 & 3.90 & 3.07 & 2.14 & 0.82 \\
\hline
\end{tabular}

merical simulation presents better agreement with the wind measurements than the global model and the gridded satellite wind estimations. Although the global wind model assimilates the satellite information, the Weibull distribution of the high-resolution model presents a better level of agreement with the observations. A snapshot of the SeaWinds product was compared with the numerical outputs in Fig. 5. Wind patterns from both products present a significant level of agreement in both components, assuming the coarser resolution of the SeaWinds. Additional verification is presented in Table 2 using model-observation statistics in terms of wind intensity for the whole year of 2012. The correlation coefficient $(R)$ is almost 0.8 and the root mean square error (RMSE) and the bias are smaller than the mean and the standard deviation obtained from the observations. In summary, modelled winds show an acceptable level of agreement with the observations.

In Fig. 6, time series comparing the results obtained from the coupled SWAN model (mesh O3) and the buoy measurements (see position in Fig. 1) are shown. The time series comparison corresponds to the significant wave height $\left(H_{\mathrm{S}}\right)$, the mean wave period $\left(\mathrm{Tm}_{01}\right)$ and the mean wave direction $\left(\theta_{\mathrm{w}}\right)$. Table 2 presents the error statistics for the whole year for mesh $\mathrm{O} 3$ in terms of $H_{\mathrm{s}}$ and $\mathrm{Tm}_{01}$. In general, the model reproduces the observed values in terms of mean behaviour and variability. Error statistics are similar with previous numerical investigations in the region; Pallares et al. (2014) obtained values of $R$ range from 0.68 to 0.91 for $H_{\mathrm{s}}$.

Figure 7 (right panel) shows a snapshot of the waves' directional spectra during the wind jet period selected at the measuring point; the results reveal the tendency to develop bimodal directional spectra due to the co-existence of sea and swell waves. Directional spectra presents a peak around $315^{\circ}$ mean wave direction associated with the growing wave due to the wind jet and another peak around $135^{\circ}$ associated with the swell. Despite the limited fetch, larger wave frequencies (smaller wave period) are obtained for the $315^{\circ}$ wave direction peak than for the $135^{\circ}$ wave direction peak. In Fig. 7 (left panel) the directional spectra for a period with- 

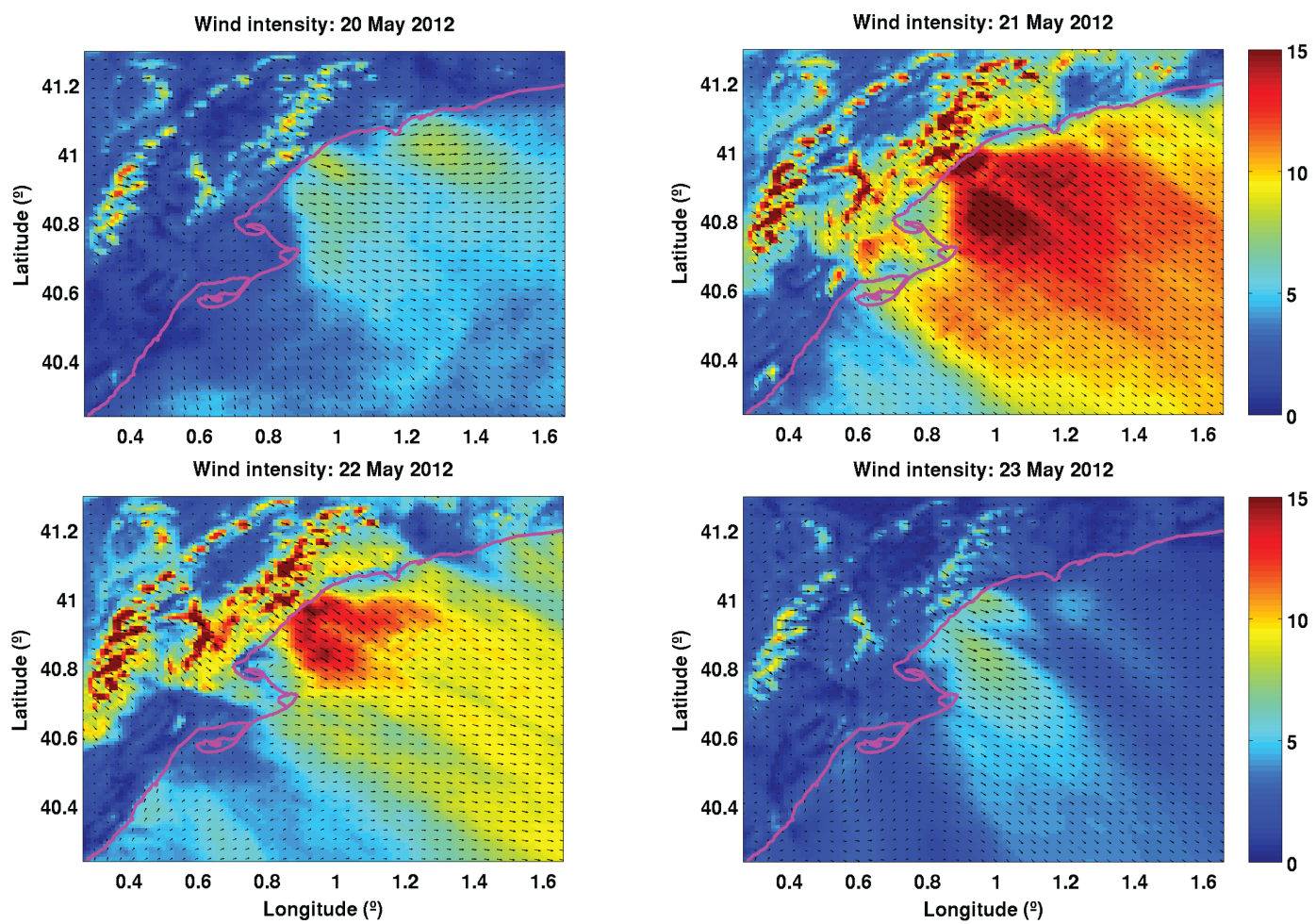

Figure 3. Sequence of the wind jet intensity on 4 days for a wind jet event in the domain of the Catalan coast. The quiver is shown for each of the three points. Results obtained for COAWST at mesh M3 are plotted.

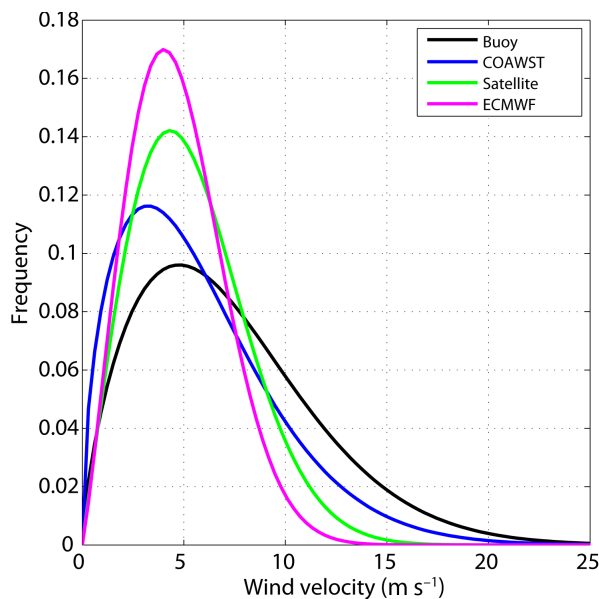

Figure 4. Weibull distribution adjustment for the wind velocities regarding the duration for the entire 12 months analysed.

out a wind jet are also shown for comparison. In this case, unimodal wave spectra are obtained. In summary, the highresolution mesh $(\mathrm{O} 4)$ is able to capture the bimodal spectra during a wind jet. Unfortunately, only the statistical spectra parameters were recorded in the buoy measurements, and full spectra comparison is not possible.
The water circulation observed at the buoy is characterised by an alignment of the flow following the isobaths. The principal component analysis of the flow for the observed depth-averaged currents reveals an angle similar to the coastline orientation $\left(\sim 26^{\circ}\right)$. As the cross-shelf flow is limited by the coastline, the variability in this direction is smaller than in the along-shelf direction: standard deviation is $2.3 \mathrm{~cm} \mathrm{~s}^{-1}$ in the cross-shelf direction vs. $7.4 \mathrm{~cm} \mathrm{~s}^{-1}$ in along-shelf direction. However, the water circulation during the wind jet events shows a different pattern. During these events, the cross-shelf flow variability increases $\left(3.8 \mathrm{~cm} \mathrm{~s}^{-1}\right.$ for the wind jet event selected), with either twolayer flow or an offshore flow in the whole water column. As an example of water current response during wind jet event, the along-shelf and cross-shelf velocities are shown in Fig. 8 for May 2012 at the observational point (negative values mean south-westward/onshore and positive northeastward/offshore). The surface currents in the cross-shelf direction intensify, causing an eventual two-layer flow during the peak of the wind intensity (21 May). When the wind jet calms down, the cross-shelf velocities are small while the along-shelf flow intensity is larger than that of the cross-shelf. The along-shelf current observed during wind jet events tends to reverse from south-westward to northeastward. 

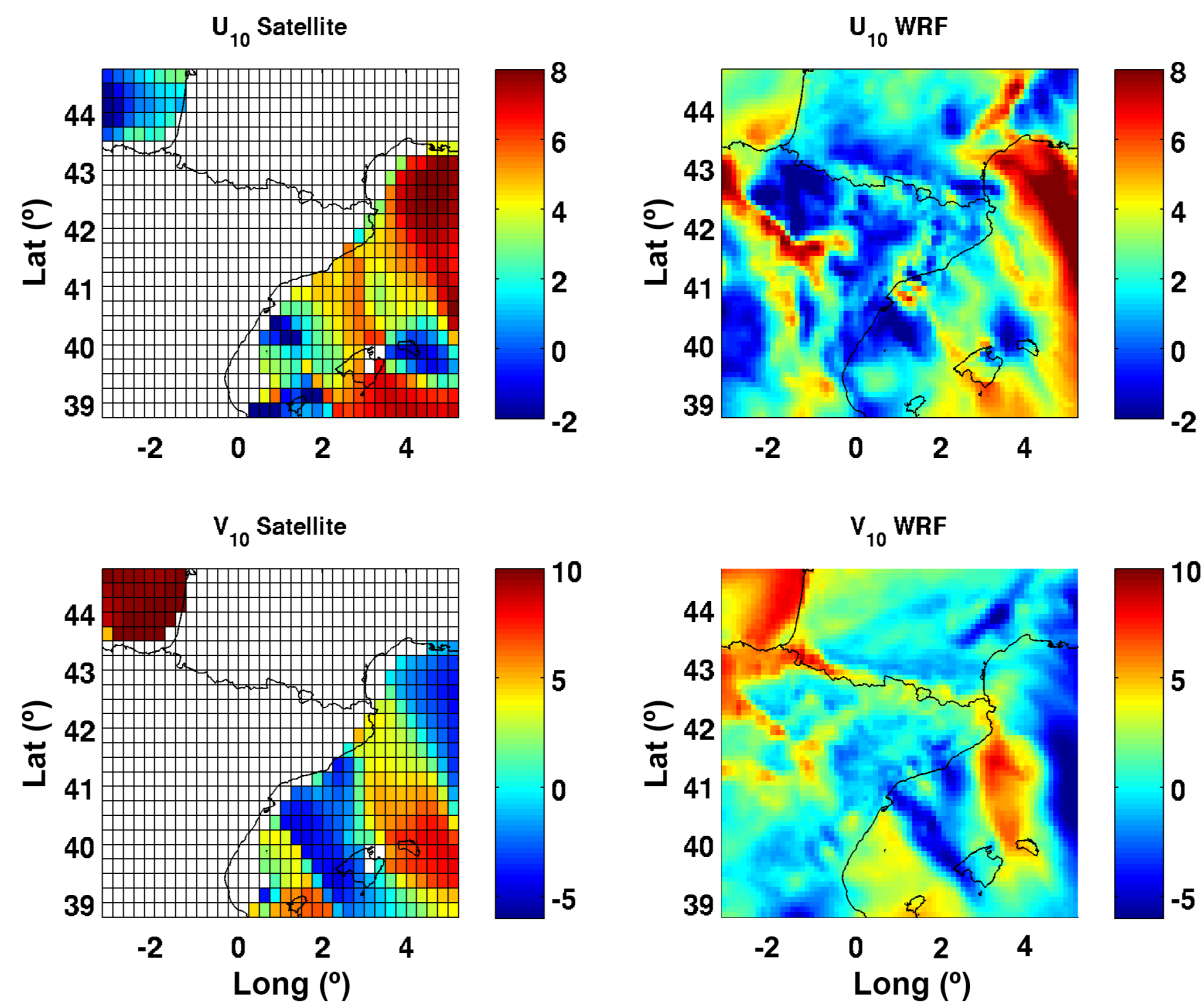

Figure 5. Wind components (top panels: east-west top; bottom panels: north-south) from the satellite gridded product for the study area (top panels) and from the results of the meteorological model (mesh M1). The figure corresponds to 1 January 2012 at 12:00 UTC.
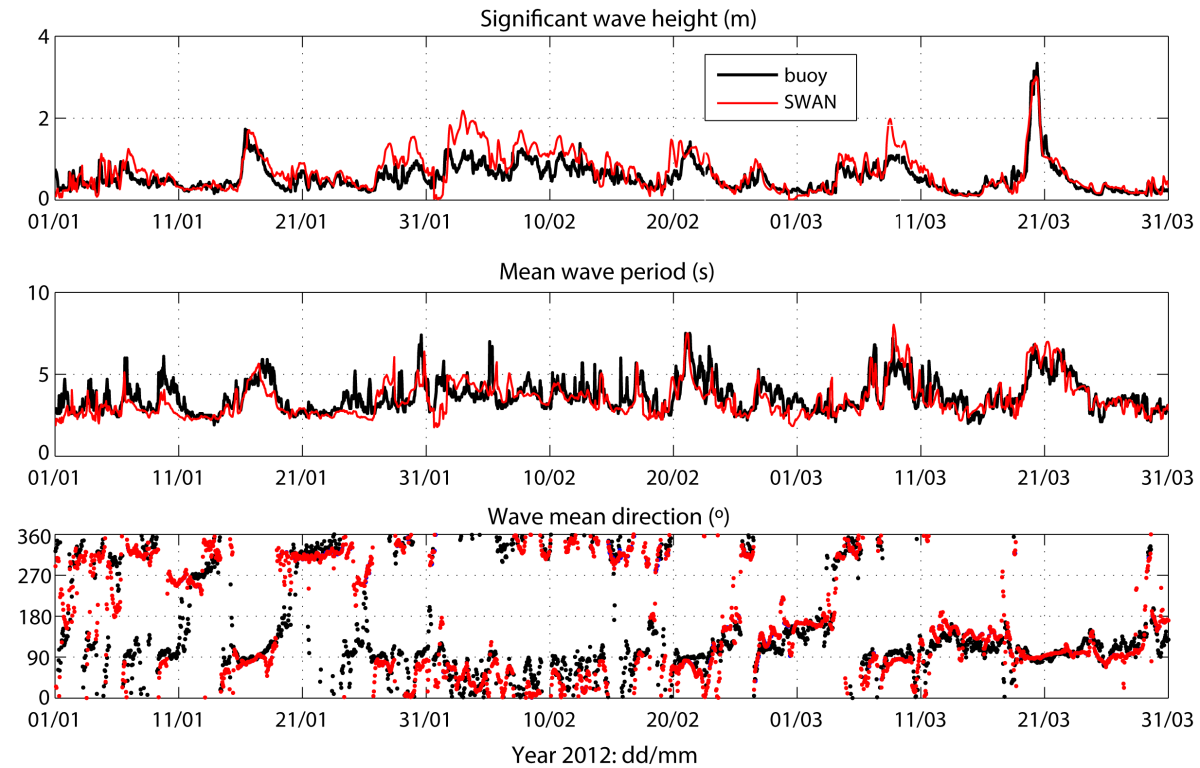

Figure 6. Time series of the significant wave height $(\mathrm{m})$, the mean wave period $\mathrm{Tm}_{01}(\mathrm{~s})$ and the mean wave direction for the first trimester of 2012. In black the buoy measurement is represented and in red the SWAN numerical results.

The skill assessment of the numerical results in terms of current (water velocity) was carried out following a similar scheme to the one used for winds and waves. The numerical model validation with ADCP observations shows an accept- able level of agreement according to the comparison for the wind jet event. For instance, Fig. 8 shows a noticeable agreement between the observed and modelled currents in the water column for both along- and cross-shelf components. In 

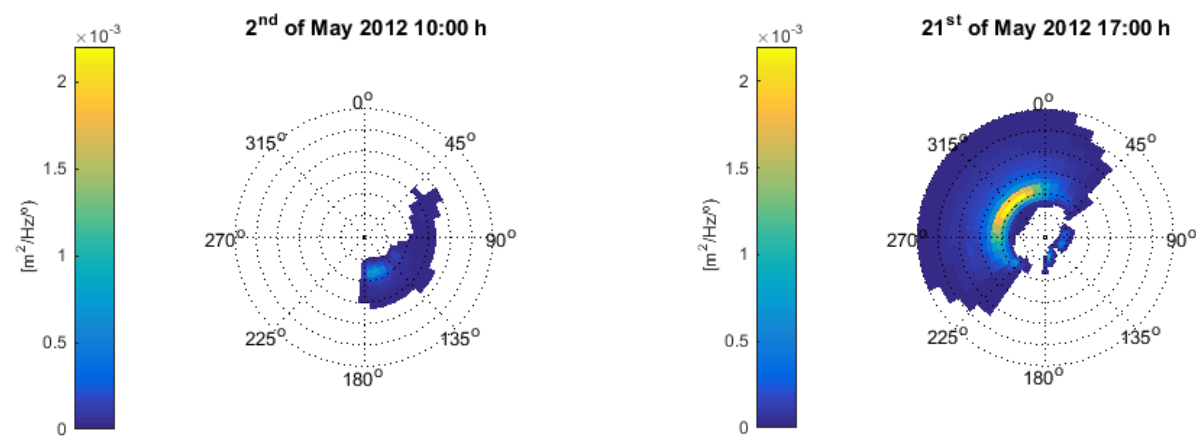

Figure 7. Numerical wave spectra for two different instants at the observational point: without wind jet event (left panel: 2 March 2012) and during wind jet event (right panel: 21 March 2012).
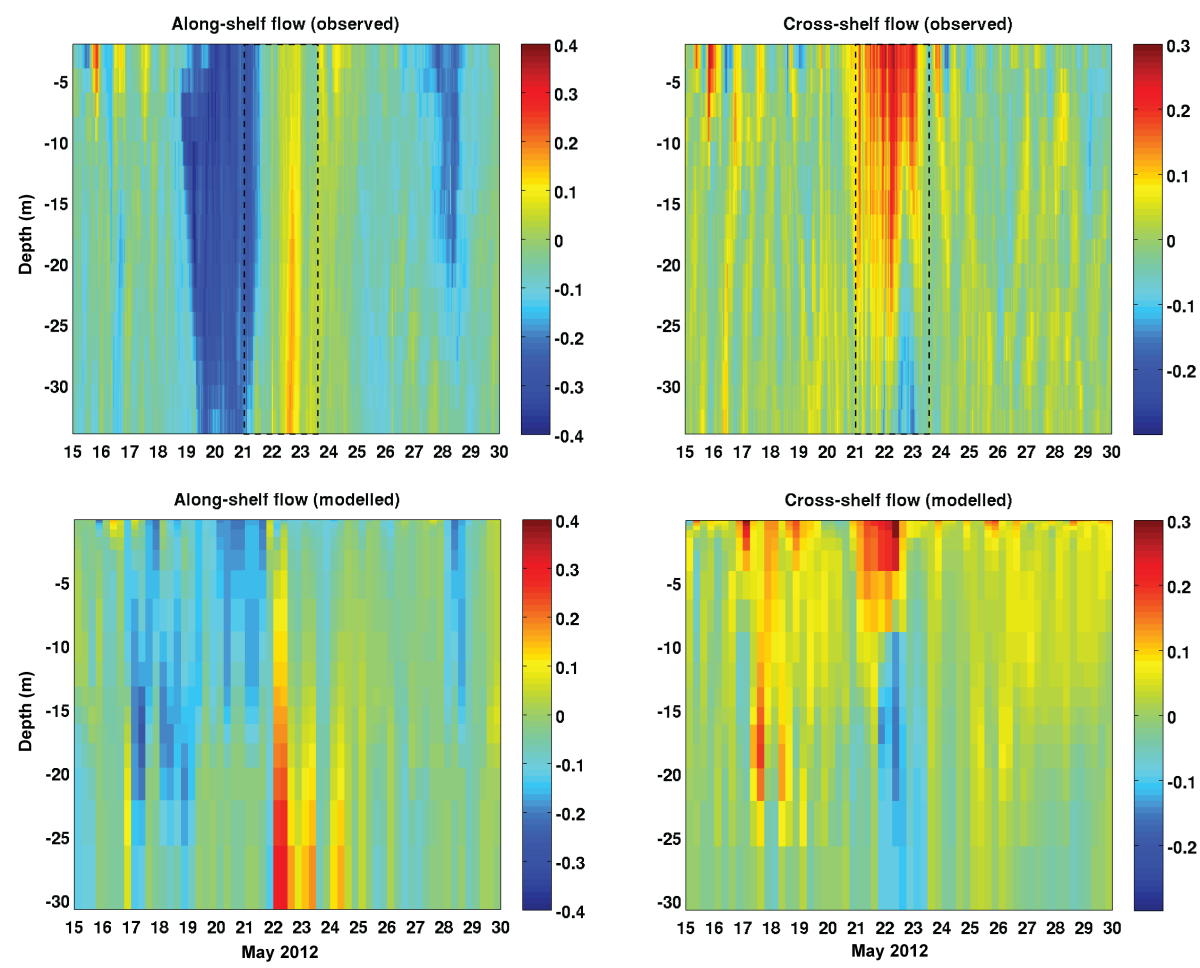

Figure 8. Along-shelf (left panels) and cross-shelf (right panels) velocity observed (top panels) and modelled (bottom panels) during May 2012 (in $\mathrm{ms}^{-1}$ ). Positive means north-eastward and offshore. The wind jet period is marked as a dashed square in the observed values. Note the different velocity ranges between cross-shelf and along-shelf plots.

addition, Table 2 presents the error statistics for the depthaveraged velocity measurements compared with the numerical model results for the wind jet event. Skill assessment is better in depth-averaged along-shelf flow in comparison to cross-shelf (e.g. $R$ equal 0.82 to vs. 0.24 ) due to the frequent two-layer flow structure observed in cross-shelf measurements during wind-jet events giving rise to a weak depthaveraged cross-shelf velocity.

The spatial water circulation modelled during the wind jet event (21 May) is shown in Fig. 9 for two different depths: sub-surface $(2 \mathrm{~m}$ water depth) and intermediate $(50 \mathrm{~m}$ water depth) for O3 mesh. Depth-averaged velocities are also presented in Fig. 9. The surface current modelled at $1 \mathrm{~km}$ (mesh O3) and $250 \mathrm{~m}$ (mesh O4) grid resolution presents a relatively homogeneous offshore direction qualitatively that is well correlated with the spatial distribution of the wind intensity. In this case, the surface current is seldom affected by topographic features such as the Ebro delta. Consistent with Fig. 8, at deeper layers the flow direction turns onshore, resulting in a two-layer flow in which the current intensity is lower than that of the surface layer (Fig. 9, centre panel). The depth-averaged flow is small due to the balance between the sheared two-layer flow; however, a flow component slightly appears that is aligned with the isobaths in the deeper areas 
Table 3. Statistics for the comparison between buoy measurements and model outputs. $W$ is the wind intensity (in $\mathrm{m} \mathrm{s}^{-1}$ ); $H_{\mathrm{S}}$ is the significant waves height (in $\mathrm{m}$ ). Statistics are only for the wind jet event (i.e. from 20 to 23 May 2012).

\begin{tabular}{|c|c|c|c|c|c|}
\hline & & $\begin{array}{l}\text { Mean } \\
\text { obs/mod }\end{array}$ & $\begin{array}{c}\text { SD } \\
\text { obs/mod }\end{array}$ & RMSE & $R$ \\
\hline \multirow{2}{*}{ 光 } & $W$ & $10.93 / 11.48$ & $5.65 / 5.19$ & 4.75 & 0.62 \\
\hline & $H_{\mathrm{S}}$ & $0.74 / 0.73$ & $0.27 / 0.32$ & 0.25 & 0.61 \\
\hline \multirow{2}{*}{ I } & $W$ & $10.93 / 11.51$ & $5.65 / 5.24$ & 4.83 & 0.61 \\
\hline & $H_{\mathrm{S}}$ & $0.74 / 0.72$ & $0.27 / 0.31$ & 0.26 & 0.61 \\
\hline \multirow{2}{*}{$\frac{\sqrt[T]{\alpha}}{\overrightarrow{0}}$} & $W$ & $10.93 / 11.46$ & $5.65 / 5.24$ & 4.79 & 0.61 \\
\hline & $H_{\mathrm{s}}$ & $0.74 / 0.72$ & $0.27 / 0.31$ & 0.26 & 0.62 \\
\hline \multirow{2}{*}{$\begin{array}{r}\mathscr{H} \\
0 \\
0\end{array}$} & $W$ & $10.93 / 11.47$ & $5.65 / 5.22$ & 4.85 & 0.60 \\
\hline & $H_{\mathrm{S}}$ & $0.74 / 0.72$ & $0.27 / 0.31$ & 0.26 & 0.61 \\
\hline
\end{tabular}

of the continental shelf. Related to that, a clear signal of the slope current is observed in the results at $-50 \mathrm{~m}$ and depthaveraged currents.

\subsection{Ocean surface roughness numerical experiments}

The wind intensity and the significant wave height during the selected wind jet event for the four simulations are shown in Fig. 10 (for the control and observational points shown in Fig. 1). Comparing the numerical results and the observations (Fig. 10, upper panels), all the numerical simulations reproduce the wind intensity and the significant wave height with a similar level of agreement. The uncoupled (CHK) and coupled simulations (e.g. T-Y, OOST and DRE) only present differences in the numerical outputs during the joint occurrence of strong winds and wave peaks in the control point. Waves and wind intensity numerical results at the observational point do not present significant changes among the four simulations due to the limited fetch conditions, which means lower significant wave height in comparison to the control point. During the calm period (at beginning and end of the wind jet event) the differences among the four simulations are inappreciable. Numerical coupled results do not present better agreement at the observational point than the uncoupled mode results. Comparing the error statistics for the observational point among the three coupled numerical simulations, we cannot assure which formulation ensures a better skill assessment (Table 3). At the control point the magnitude of the wind intensity and the significant wave height is larger for the uncoupled simulation (CHK) in comparison to the coupled simulations (Fig. 10, bottom panels). Maximum differences of $3 \mathrm{~m} \mathrm{~s}^{-1}$ in wind intensity and $0.3 \mathrm{~m}$ in significant wave height are obtained if we compare OOST and CHK simulations. In consequence, small differences are found between coupled and uncoupled simulations when wave conditions increases.

\section{Discussion}

The shape of the wind jet modelled is benefited by the highresolution meshes used in our investigation. According to our results, the wind jet approximately covers an area of $50 \mathrm{~km}$ width offshore. This area is in agreement with the wind intensity atlas provided by the Spanish Ministry of Energy (see Fig. 11) obtained from a long-term reanalysis product (15 years using the MASS model). In this sense, highresolution meshes used in this investigations (i.e. 1 and $3 \mathrm{~km}$ grid resolution) are suitable for an accurate wind jet modelling. As it was pointed out by Alomar et al. (2014) and Cerralbo et al. (2015), the relevance of winds in the ocean response in terms of waves and currents justifies the highresolution in the modelling investigations in the Ebro delta region.

Our results have shown an acceptable representation of the bimodal structure of the significant wave height and support the conclusions highlighted by Alomar et al. (2014), who note that a high spatial resolution of the wind field is required to represent an acceptable numerical wave field in very limited fetch conditions. The occurrence of bimodal wave features may also have different implications: the first one is that, because of the spatial resolution, the local northwesterly wind that produced the second peak of spectra may not have been detected in previous investigations (SánchezArcilla et al., 2008; Alomar et al., 2014). The second implication is related to the momentum transfer: several authors have highlighted that under mixed wave-train conditions the ocean surface roughness may increase appreciably (SánchezArcilla et al., 2008). Also, the wave modelling deserves to be mentioned particularly with regard to the good fit of wave results in comparison to previous investigations (BolañosSanchez et al., 2007; Sánchez-Arcilla et al., 2008). Statistical errors were reduced significantly due to the young sea developed in the wind jet region likely thanks to the modification of a parameter relative to whitecapping dissipation (Pallares et al., 2014). In particular, smaller root mean square errors were obtained in the mean wave period variable, which presented large uncertainty (Bolaños-Sanchez et al., 2007; Sánchez-Arcilla et al., 2008; Alomar et al., 2014).

As we noted in the Results section, the water circulation pattern showed differential behaviour for the long-term water circulation in comparison to the wind jet event. For the long-term circulation and in the shallow region, the frictional response prevails, with the along-shelf flow variability being larger than the cross-shelf flow, similar to other investigations in the inner and mid-shelf (see review in Lentz and Fewings, 2012; Grifoll et al., 2013). However, a different picture occurs during the wind jet event. In this case a characteristic surface current is high correlated to the offshore wind. According to the numerical outputs and in situ observations shown in Fig. 8, a deeper onshore flow, opposing the surface layer flow offshore, is developed. This flow is relatively weak due to the prevalence of the along-shelf com- 

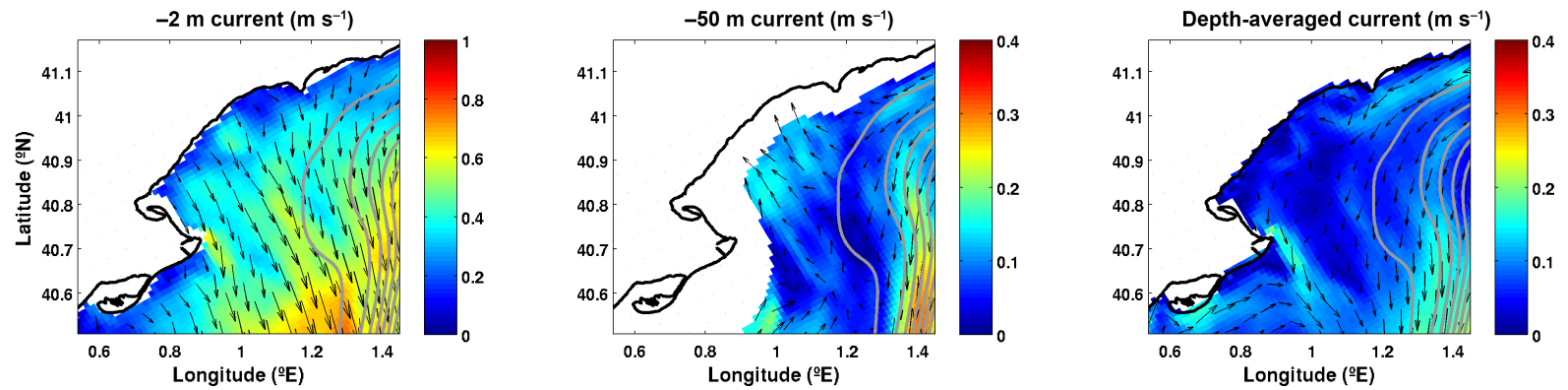

Figure 9. Modelled circulation at $-2 \mathrm{~m}$ (left panel), $-50 \mathrm{~m}$ (centre panel) and depth-averaged circulation (right panel) during the peak of the wind jet event (i.e. 21 May 2012, 06:00 UTC). The quiver is shown for each of the four computational points. Grey lines are shown for each of the 100 isobaths. Note differences in the velocity ranges among the sub-plots.
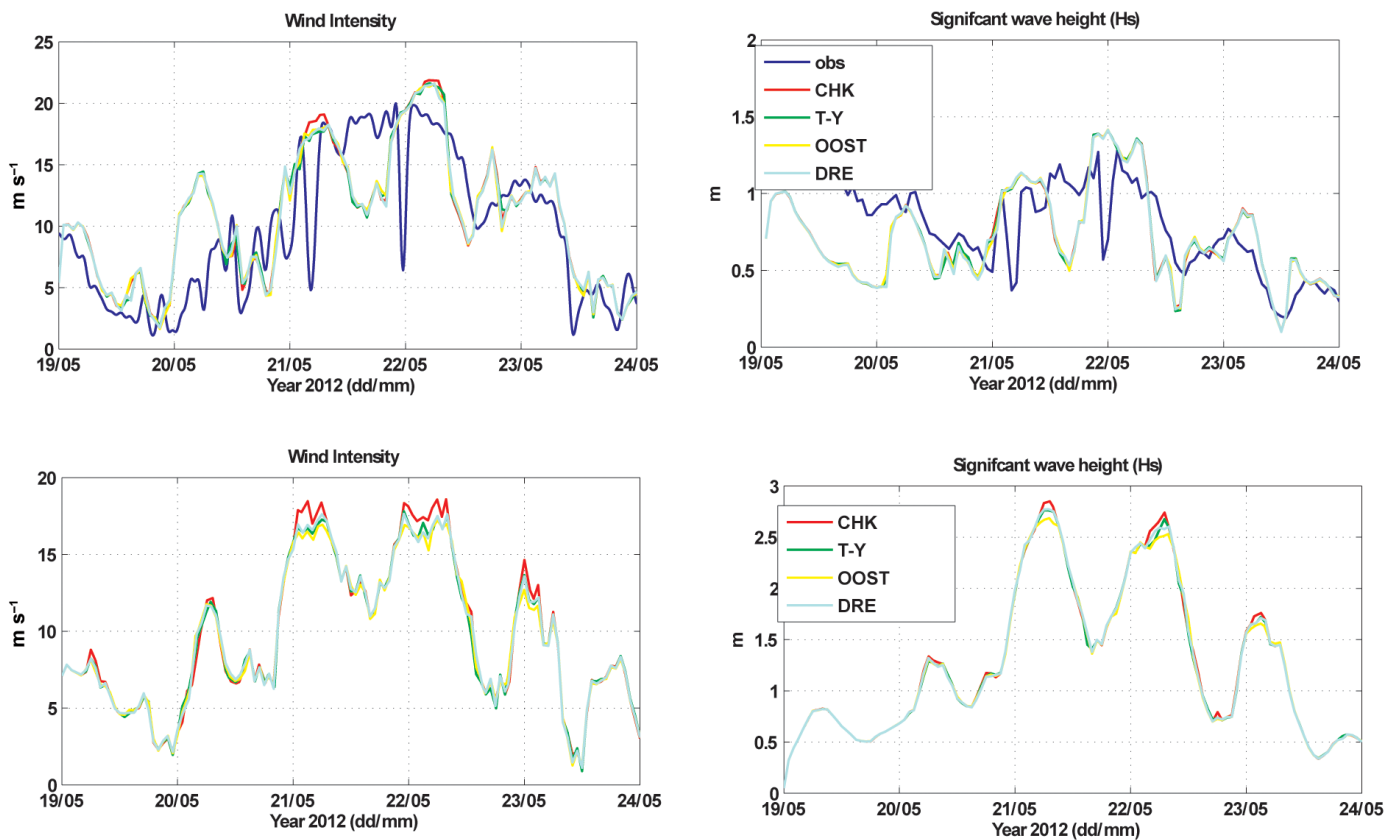

Figure 10. Wind intensity (left panels) and significant wave height (right panels) for the wind jet energetic event for the observational (top panels) and control (bottom panels) points.

ponent that increases offshore. These circulation patterns are consistent with other investigations (e.g. Horwitz and Lentz, 2014; Fewings et al., 2008; Dzwonkowski et al., 2011) where a well-developed two-layer flow due to intense cross-shelf winds tends to occur when the turbulent layers overlap (water depth in the inner shelf is of the order of metres to tens of metres according to Lentz and Fewings, 2012). In the mid- and outer shelf, the flow tends to be oriented in the along-shelf direction due to the prevalence of the regional response to the wind jet and the slope current. In this sense, the frictional adjustment time due to the wind (inversely proportional to the depth) varies in the continental shelf section and may be of the order of days in the mid-/outer shelf (Csanady, 1982). As a consequence, the expected response at deeper layers will also be dependent on processes acting at larger scales than the wind jet (i.e. baroclinic forcing, mesoscale activity) such as the slope current signal observed at $50 \mathrm{~m}$ water depth and depth-averaged currents in the numerical results (Fig. 9). The along-shelf flow in the inner shelf is presumably influenced by the regional response to the wind jet at the stratification in the water column and the barotropic pressure gradient adjustment due the spatial wind variability. These factors play an important role in the resultant water circulation pattern and its variability deserves additional numerical efforts and extended local wind and sea level information. For instance, Oey et al. (2004) and Liu and Weisberg (2012) include extended measurements to investigate the water circulation's response to spatial wind and the particular role of the barotropic pressure gradients. Finally, it is worth noting that the interaction between offshore winds and regional cir- 


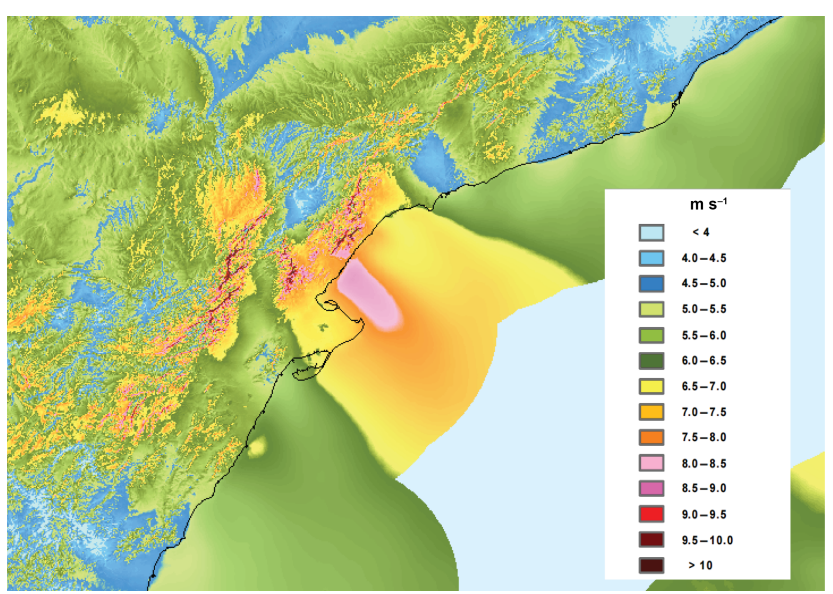

Figure 11. Wind atlas annual mean wind speed at $30 \mathrm{~m}$ height from a reanalysis product (source: Spanish Ministry of Energy, 2014).

culation was filtered in previous investigations in the region (Font, 1990; Salat et al., 2002; Jordà, 2005).

Several investigations have found the importance of the sea state in the impact on the air-sea momentum flux; in particular the calculations based on the Charnock constant underestimated the air-sea momentum transfer (e.g. Janssen and Viterbo, 1996; Drennan et al., 2003), which can be significant under mixed seas (Sanchez-Arcilla et al., 2008). In the northern margin of the Ebro delta and during the wind jet, no relevant differences were found when comparing the significant wave period and the wind intensity between the numerical model and observations for the observational point. During calm periods, the averaged conditions prevail over energetic events, so the feedback of the air-sea momentum does not show significant differences. The detailed analysis of 21-22 May event showed significant differences between the coupled and uncoupled cases for significant wave height and wind intensity offshore of the wind jet (e.g. control "offshore" point). When we compare the coupling numerical results (i.e. T-Y, OOST and DRE) versus CHK results, we observe that the wind intensity at the control point is affected significantly by the sea state during the energetic event. For the coupling simulations the wind intensity is reduced due to the increasing wave-induced ocean surface roughness. This behaviour is consistent with other coupling atmosphere-ocean investigations under a high level of meteorological energy (e.g. Olabarrieta et al., 2012). In parallel, the wave field is modified by the feedback between wave and wind stress. During the energetic wind event selected, $H_{\mathrm{S}}$ is lower in comparison to the uncoupled case (CHK), consistent with other numerical experiments (Webber et al., 1993; Warner et al., 2010; Olabarrieta et al., 2012) and observational investigations (Yelland et al., 1998; Edson, 2008), which found that the momentum flux is underestimated using the Charnock constant parameter. Unfortunately, the lack of measurements offshore of the observational point (i.e. larger fetch in comparison to observational point) has not allowed one to investigate if the coupling simulations present better skill assessment than the uncoupled case.

Differences in the primitive variables between the coupled and uncoupled simulations during particular energetic events are relatively small in terms of wind intensity and significant wave height. Furthermore, the assessment of the wind energy resource is relevant in this region with a high potential for wind farm installation due to the large and persistent wind intensity and the relatively large spatial extension of the continental shelf. A simple way to estimate turbine power from wind intensity is based on the idealised machine of blade diameter $(D)$ being equal to $100 \mathrm{~m}$ (Manwell et al., 2002):

$P=\rho(2 / 3 D)^{2} W^{3}$.

Wind intensity $(W)$ simulations are taken at $10 \mathrm{~m}$ height, so a log-law-based conversion is used to obtain wind values at $80 \mathrm{~m}$ (typical value of turbine hubs). With the converted values of the numerical simulations, we estimate the idealised wind power for the period 21-22 May 2012 at the control point. The power using the CHK wind value is $8.087 \mathrm{~kW}$ (average wind speed of $11.41 \mathrm{~m} \mathrm{~s}^{-1}$ ); in contrast, using OOST formulations leads to a power of $7.207 \mathrm{~kW}$ (average wind speed of $10.98 \mathrm{~m} \mathrm{~s}^{-1}$ ). Intermediate values are obtained for T-Y and DREN formulations: 7.365 and $7.346 \mathrm{~kW}$, respectively. The cubic relationship between wind power and wind velocity highlights the importance of accurate estimations of wind intensity for wind energy resources using coupling techniques (a maximum percentage of $10 \%$ is assessed). This example shows the relevance of coupled effects for an accurate wind power assessment for wind farm project plans.

The wave-limited fetches and the persistent offshore winds represent particular ocean-atmosphere conditions never investigated before from a full-coupling perspective; only energetic cyclogenesis activity and extreme conditions have been recently modelled and investigated (e.g. Warner et al., 2010; Olabarrieta et al., 2012; Renault et al., 2012; Zambon et al., 2014; Ricchi et al., 2016) where also the heat transfer plays a relevant role in the air-sea coupling. In the mentioned cases, extreme modelled waves and wind benefitted from the use of full-coupling systems. Our case only presents comparable energetic conditions during a very short period of time; however, the cubic relationship between the potential wind energy and the wind intensity may justify, for engineering purposes, the use of coupled formulations between wind and waves. Further observational campaigns and the future use of high-resolution remote-sensing products (e.g. Sentinel-1 and Sentinel-3; Torres et al., 2012; Malenovsky et al., 2012) will benefit the numerical results and extended physical investigations in such a complex process as wind jet, in particular the role of the air-sea transfer formulations. Our results are also relevant in that they may be useful for further physical investigations in similar domains where the wind jets control the ocean-atmosphere dynamics (Jiang et al., 2009; Barton et al., 2009; Shimada and Kawamura, 2006). 


\section{Conclusions}

Wind jet events, investigated using numerical modelling and both in situ and remote-sensing data, present particular conditions in meteo-oceanographic variables in the northern margin of the Ebro delta. A fully coupled meteooceanographic numerical model was implemented, with a good level of agreement in terms of waves, currents and wind fields measured. The numerical results reveal a spatially varying wind pattern, forming a well-limited wind jet. The water current velocity pattern during wind jet is well correlated with the wind intensities in the surface layer. However, in deep layers the flow becomes complex, and other processes of larger temporal and spatial characteristic scales affect the water circulation. The wave modelling during the wind jet event is characterised by the development of bimodal wave spectra: local wave generation due to wind jet and waves propagated from the open sea. Numerical results from sensitivity tests have shown the relatively small relevance of air-sea transfer formulations considering the significant wave height for the ocean surface roughness estimation. Furthermore, the accurate estimation of the wind energy resource may be benefitted by the coupled numerical modelling. The characteristics of the meteo-ocean variables during the wind jet in the northern Ebro delta may be useful for understanding processes in similar domains under severe cross-shelf wind conditions. 


\section{Appendix A: Modification of the whitecapping term in SWAN}

Pallares et al. (2014) performed numerical experiments that aimed to improve the numerical wave predictions in semienclosed bays, modifying the dissipation terms in the wave energy balance equation. For this purpose two whitecapping formulations are considered in SWAN, obtained from the pulse-based model of Hasselmann (1974) reformulated in terms of wave number (the WAMDI group, 1988):

$S_{\mathrm{ds}, \mathrm{w}}(\sigma, \theta)=-\Gamma \widetilde{\sigma} \underset{\widetilde{k}}{\frac{k}{\widetilde{k}}} E(\sigma \theta)$,

where $\widetilde{\sigma}$ and $\widetilde{k}$ denote the mean frequency and the mean wave number, respectively, and the coefficient $\Gamma$ depends on the wave steepness (Janssen, 1991):

$\Gamma=C_{\mathrm{ds}}\left((1-\delta)+\delta \frac{k}{\widetilde{k}}\right)\left(\frac{\widetilde{s}}{\widetilde{s}_{\mathrm{PM}}}\right)^{p}$.

The coefficients $C_{\mathrm{ds}}, \delta$ and $p$ can be adapted to the study case; $\widetilde{s}$ is the overall wave steepness; and $\widetilde{s}_{\mathrm{PM}}$ is the value of $\widetilde{s}$ for the Pierson-Moskowitz spectrum.

In SWAN the previously mentioned coefficients are obtained by adjusting the energy balance for idealised wave growth conditions (fully developed wind seas in deep water), despite the wave growth in semi-enclosed domains with highly variable wind fields differing considerably from those idealised conditions. As a result of a calibration process in the NW Mediterranean Sea, which led to a reduction of the wave forecast errors mainly present in the wave period, the coefficients selected for the wind jet region were $\delta=1$, $C_{\mathrm{ds}}=2.36 \times 10^{-5}$ and $p=4$, achieving a notable fit between numerical outputs and wave observations.
Appendix B: Air-sea momentum transfer formulations (bottom roughness length)

The standard bottom roughness length scale is expressed as a function of the Charnock coefficient $\left(C_{\mathrm{a}}\right.$; typical value of 0.016) and surface wind stress $\left(u_{\mathrm{s}}\right)$ :

$z_{0}=C_{\mathrm{a}} \cdot u_{\mathrm{s}}^{2} / g$,

where $g$ is the gravity. Coupling online simulations in COAWST allows for three different formulations to be chosen to parameterise the bottom roughness considering the wave effects. The formulation of Taylor and Yelland (2001) considers the wave effects:

$z_{0} / H_{\mathrm{S}}=1200 \cdot\left(H_{\mathrm{s}} / L_{\mathrm{p}}\right)^{4.5}$,

where $H_{\mathrm{s}}$ is the significant wave height and $L_{\mathrm{p}}$ is the wavelength at the peak of the wave spectrum. Drennan et al. (2003) proposed a formulation to estimate $z_{0}$ as a function of the phase-wave speed $\left(C_{\mathrm{p}}\right)$ and wind friction velocity $\left(u^{*}\right)$ :

$z_{0} / H_{\mathrm{s}}=3.35 \cdot\left(u^{*} / C_{\mathrm{p}}\right)^{3.4}$.

Similar to Drennan's formulation, Oost et al. (2002) proposed the following formulation based on an experimental data set:

$z_{0} / L_{\mathrm{p}}=25.0 / \pi \cdot\left(u^{*} / C_{\mathrm{p}}\right)^{4.5}$

Conceptual differences arise from these formulations: Taylor and Yelland (2001) considers the wave steepness, Drennan et al. (2003) is based on the wave age and Oost et al. (2002) considers effects of both wave steepness and wave age. 
Acknowledgements. The authors are thankful to Joan Puigdefàbregas (LIM/UPC, Barcelona), Joaquim Sospedra (LIM/UPC, Barcelona) and Jordi Cateura (LIM/UPC, Barcelona) for the data acquisition. The research leading to these results and data acquisition received funding from Mestral (CTM-2011-30489), Neptune (KIC project 006-2012-R01-IREC-OFF-AERO), Hareamar/Dardo (ENE2012-38772-C02-02), Rises-AM (GA603396), iCOAST project (ECHO/SUB/2013/661009) and MINECO and FEDER who fund Plan-Wave (CTM2013-45141-R).

Edited by: J. von Hardenberg

Reviewed by: two anonymous referees

\section{References}

Alomar, M., Sánchez-Arcilla, A., Bolaños, R., and Sairouni, A.: Wave growth and forecasting in variable, semi-enclosed domains, Cont. Shelf Res., 87, 28-40, doi:10.1016/j.csr.2014.05.008, 2014.

Barton, E. D., Lavín, M. F., and Trasviña, A.: Coastal circulation and hydrography in the Gulf of Tehuantepec, Mexico, during winter, Cont. Shelf Res., 29, 485-500, doi:10.1016/j.csr.2008.12.003, 2009.

Bolaños-Sanchez, R., Sanchez-Arcilla, A., and Cateura, J.: Evaluation of two atmospheric models for wind-wave modelling in the NW Mediterranean, J. Mar. Syst., 65, 336-353, doi:10.1016/j.jmarsys.2005.09.014, 2007.

Booij, N., Ris, R. C., and Holthuijsen, L. H.: A third-generation wave model for coastal regions: 1 . Model description and validation, J. Geophys. Res., 104, 7649, doi:10.1029/98JC02622, 1999.

Cerralbo, P., Grifoll, M., Moré, J., Bravo, M., Sairouní Afif, A., and Espino, M.: Wind variability in a coastal area (Alfacs Bay, Ebro River delta), Adv. Sci. Res., 12, 11-21, doi:10.5194/asr-12-112015, 2015.

Csanady, G. T.: Longshore pressure gradients caused by offshore wind, J. Geophys. Res., 85, 1076, doi:10.1029/JC085iC02p01076, 1980.

Csanady, G. T.: Circultion in the coastal ocean, Adv. Geophys., 23, 101-183, 1982.

Drennan, W. M., Graber, H. C., Hauser, D., and Quentin, C.: On the wave age dependence of wind stress over pure wind seas, J. Geophys. Res., 108, 8062, doi:10.1029/2000JC000715, 2003.

Drews, C.: Using wind setdown and storm surge on Lake Erie to calibrate the air-sea drag coefficient, PLoS One, 8, e72510, doi:10.1371/journal.pone.0072510, 2013.

Durand, N., Fiandrino, A., Fraunié, P., Ouillon, S., Forget, P., and Naudin, J. J.: Suspended matter dispersion in the Ebro ROFI: an integrated approach, Cont. Shelf Res., 22, 267-284, doi:10.1016/S0278-4343(01)00057-7, 2002.

Dzwonkowski, B., Park, K., and Jiang, L.: Subtidal across-shelf velocity structure and surface transport effectiveness on the Alabama shelf of the northeastern Gulf of Mexico, J. Geophys. Res., 116, C10012, doi:10.1029/2011JC007188, 2011.

Edson, J. B.: Review of air-sea transfer processes, paper presented at ECMWF Workshop on Ocean-Atmosphere Interactions, Eur. Cent. For Medium-Range Weather Forecasts, 10-12 November 2008, Reading, UK, 2008.
Fewings, M., Lentz, S. J., and Fredericks, J.: Observations of Cross-Shelf Flow Driven by Cross-Shelf Winds on the Inner Continental Shelf, J. Phys. Oceanogr., 38, 2358-2378, doi:10.1175/2008JPO3990.1, 2008.

Font, J.: A Comparison of Seasonal Winds With Currents on the Continental Slope of the Catalan Sea (Northwestern Mediterranean), J. Geophys. Res., 95, 1537-1545, doi:10.1029/JC095iC02p01537, 1990.

Grifoll, M., Aretxabaleta, A. L., Pelegrí, J. L., Espino, M., Warner, J. C., and Sánchez-Arcilla, A.: Seasonal circulation over the Catalan inner-shelf (northwest Mediterranean Sea), J. Geophys. Res.-Oceans, 118, 5844-5857, doi:10.1002/jgrc.20403, 2013.

Grifoll, M., Aretxabaleta, A., and Espino, M.: Shelf response to intense offshore wind, J. Geophys. Res., 120, 6564-6580, doi:10.1002/2015JC010850, 2015.

Haidvogel, D. B., Arango, H. G., Hedstrom, K., Beckmann, A., Malanotte-Rizzoli, P., and Shchepetkin, A. F.: Model evaluation experiments in the North Atlantic Basin: Simulations in nonlinear terrain-following coordinates, Dynam. Atmos. Oceans, 32, 239-281, 2000.

Hasselmann, K.: On the spectral dissipation of ocean waves due to white-capping, Bound.-Lay. Meteorol., 6, 107-127, 1974.

Horwitz, R. and Lentz, S. J.: Inner-Shelf Response to Cross-Shelf Wind Stress: The Importance of the Cross-Shelf Density Gradient in an Idealized Numerical Model and Field Observations, J. Phys. Oceanogr., 44, 86-103, doi:10.1175/JPO-D-13-075.1, 2014.

Jacob, R., Larson, J., and Ong, E.: $M \times N$ communication and parallel interpolation in CCSM using the Model Coupling Toolkit, Preprints, Mathematics and Computer Science Division, Argonne National Laboratory, Argonne, IL, 19, 293-307, 2005.

Jansà, A.: The "Mistral-Tramuntana" shear line. A satellite observation. Scientific results of the alpine experiment (ALPEX), Grap publications series 27, Volume II, 577-591, 1985.

Janssen, P. A. E. M.: Wave-induced stress and the drag of air flow over sea waves, J. Phys. Oceanogr., 19, 745-754, 1989.

Janssen, P. A. E. M.: Consequences of the effect of surface gravity waves on the mean air flow, International Union of Theory and Applied Mechanic (IUTAM), Sydney, Australia, 193-198, 1991.

Janssen, P. A. E. M. and Viterbo, P.: Ocean waves and the atmospheric climate, J. Climate, 9, 1269-1287, 1996.

Jiang, H., Farrar, J. T., Beardsley, R. C., Chen, R., and Chen, C.: Zonal surface wind jets across the Red Sea due to mountain gap forcing along both sides of the Red Sea, Geophys. Res. Lett., 36, L19605, doi:10.1029/2009GL040008, 2009.

Jones, P.: First-and second-order conservative remapping schemes for grids in spherical coordinates, Mon. Weather Rev., 3, $2204-$ 2210, 1999.

Jordà, G.: Towards data assimilation in the Catalan continental shelf. From data analysis to optimization methods, $\mathrm{PhD}$ thesis, Univ. Politècnica de Catalunya, Barcelona, Spain, 2005.

Klaič, Z. B., Pasarič, Z., Beg Paklar, G., and Oddo, P.: Coastal sea responses to atmospheric forcings at two different resolutions, Ocean Sci., 7, 521-532, doi:10.5194/os-7-521-2011, 2011.

Lentz, S. J., and Fewings, M. R.: The wind- and wave-driven innershelf circulation, Annu. Rev. Mar. Sci., 4, 317-343, 2012.

Lionello, P., Malaguzzi, P., and Buzzi, A.: Coupling between the Atmospheric Circulation and the Ocean Wave Field: an idealized case, J. Phys. Oceanogr., 28, 161-177, 1998. 
Liu, Y. and Weisberg, R. H.: Seasonal variability on the West Florida Shelf, Prog. Oceanogr., 104, 80-98, doi:10.1016/j.pocean.2012.06.001, 2012.

Malenovsky, Z., Rott, H., Cihlar, J., Schaepman, M., García-Santos, G., Fernandes, R., and Berger, M.: Sentinels for science: potential of sentinel-1, -2 , and -3 missions for scientific observations of ocean, cryosphere, and land, Remote Sens. Environ., 120, 91$101,2012$.

Manwell, J. F., McGowan, J. G., and Rogers, A. L.: Wind power explained: theory, design and application, Wiley, West Sussex, UK, 2002.

Martín-Vide, J. and Olcina, J.: Climas y Tiempos de España, Alianza editorial, Madrid, Spain, 264 pp., 2001.

Mestres, M., Sierra, J. P., Sánchez-arcilla, A., González Del Río, J., Wolf, T., and Rodríguez, A.: Modelling of the Ebro River plume, Validation with field observations, Sci. Mar., 67, 379-391, 2003.

Nelson, J. and He, R.: Effect of the Gulf stream on winter extratropical cyclone outbreaks, Atmos. Sci. Lett., 13, 311-316, doi:10.1002/asl.400, 2012.

Nunalee, C. and Basu, S.: Mesoscale modeling of coastal low level jets: implications for offshore wind resource estimation, Wind Energy, 17, 1199-1216, doi:10.1002/we.1628, 2013.

Oey, L.-Y., Winant, C., Dever, E., Johnson, W., and Wang, D.-P.: A model of the near-surface circulation of the Santa Barbara Channel: comparison with observations and dynamical interpretations, J. Phys. Oceanogr., 34, 23-43, 2004.

Olabarrieta, M., Warner, J. C., Armstrong, B., Zambon, J. B., and He, R.: Ocean-atmosphere dynamics during Hurricane Ida and Nor'Ida: An application of the coupled ocean-atmospherewave-sediment transport (COAWST) modeling system, Ocean Model., 43-44, 112-137, doi:10.1016/j.ocemod.2011.12.008, 2012.

Oost, W. A., Komen, G. J., Jacobs, C. M. J., and van Oort, C.: New evidence for a relation between wind stress and wave age from measurements during ASGAMAGE, Bound.-Lay. Meterol., 103, 409-438, 2002.

Palanques, A., Puig, P., and Guillén, J.: Near-bottom suspended sediment fluxes on the microtidal low-energy Ebro continental shelf (NW Mediterranean), Cont. Shelf, 22, 285-303, 2002.

Pallares, E., Sánchez-Arcilla, A., and Espino, M.: Wave energy balance in wave models (SWAN) for semi-enclosed domains - Application to Catalan coast, Cont. Shelf, 87, 41-53, 2014.

Redondo, J. M., Matulka, A., Platonov, A., Sekula, E., and Fraunie, P.: Eddy measurements, coastal turbulence and statistics in the gulf of Lions, Ocean Sci. Discuss., 10, 55-81, doi:10.5194/osd10-55-2013, 2013.

Renault, L., Chiggiato, J., Warner, J. C., Gomez, M., Vizoso, G., and Tintoré, J.: Coupled atmosphere-ocean-wave simulations of a storm event over the Gulf of Lion and Balearic Sea, J. Geophys. Res.-Oceans, 117, C09019, doi:10.1029/2012JC007924, 2012.

Ricchi A., Miglietta, M. M., Falco, P. P., Bergamasco, A., Benetazzo, A., Bonaldo, D., Sclavo, M., and Carniel, S.: On the use of a coupled ocean-atmosphere-wave model during an extreme Cold Air Outbreak over the Adriatic Sea, Atmos. Res., 172-173, 48-65, 2016.

Riosalido, L., Vazquez, A., Gordo, A., and Jansà, A.: "Cierzo": nortwesterly wind along the Ebro Valley as a meso-scale effect induced on the lee of the Pyrennes mountain range; a case study during alpex special observing period, in: Scientific results of the alpine experiment (ALPEX), Volume II, Grap publications series 27, 565-575, 1986.

Rodi, W.: Examples of calculation methods for flow and mixing in stratified fluids, J. Geophys. Res., 92, 5305-5328, 1987.

Rogers, W. E., Hwang, P. A., and Wang, D. W.: Investigation of wave growth and decay in the SWAN model: three regional-scale applications, J. Phys. Oceanogr., 33, 366-389, 2003.

Salat, J., Garciab, M. A., Cruzado, A., Palanques, A., Arín, L., Gomis, D., Guillen, J., de León, A., Puigdefàbregas, J., Sospedra, J., and Velasquez, Z. R.: Seasonal changes of water mass structure and shelf slope exchanges at the Ebro Shelf (NW Mediterranean), Cont. Shelf Res., 22, 327-348, 2002.

Sánchez-Arcilla, A., González-Marco, D., and Bolaños, R.: A review of wave climate and prediction along the Spanish Mediterranean coast, Nat. Hazards Earth Syst. Sci., 8, 1217-1228, doi:10.5194/nhess-8-1217-2008, 2008.

Schaeffer, A., Garreau, P., Molcard, A., Fraunié, P., and Seity, Y.: Influence of high-resolution wind forcing on hydrodynamic modeling of the Gulf of Lions, Ocean Dynam., 61, 1823-1844, doi:10.1007/s10236-011-0442-3, 2011.

Shimada, T. and Kawamura, H.: Wind-wave development under alternating wind jets and wakes induced by orographic effects, Geophys. Res. Lett., 33, L02602, doi:10.1029/2005GL025241, 2006.

Skamarock, W. C., Klemp, J. B., Dudhia, J., Gill, D. O., Barker, D. M., Wang, W., and Powers, J. G.: A Description of the Advanced Research WRF, Version 2, NCAR Technical Note, NCAR/TN468+STR, National Center for Atmospheric Research, Boulder, Colorado, USA, 2005.

Spanish Ministry of Energy: Wind Atlas of Spain, http://www. mineturb.gov.es (last access: 14 December 2015), 2014.

Taylor, P. and Yelland, M.: The dependence of sea surface roughness on the height and steepness of the waves, J. Phys. Oceanogr., 31, 572-590, 2001.

Tonani, M., Pinardi, N., Fratianni, C., Pistoia, J., Dobricic, S., Pensieri, S., de Alfonso, M., and Nittis, K.: Mediterranean Forecasting System: forecast and analysis assessment through skill scores, Ocean Sci., 5, 649-660, doi:10.5194/os-5-649-2009, 2009.

Torres, R., Snoeij, P., Geudtner, D., Bibby, D., Davidson, M., Attema, E., Potin, P., Rommen, B., Floury, N., Brown, M., Traver, I. N., Deghaye, P., Duesmann, B., Rosich, B., Miranda, N., Bruno, C., L'Abbate, M., Croci, R., Pietropaolo, A., Huchler, M., and Rostan, F.: GMES Sentinel-1 mission, Remote Sens. Environ., 120, 9-24, 2012.

Umlauf, L. and Burchard, H.: A generic length-scale equation for geophysical, J. Mar. Res., 61, 235-265, doi:10.1357/002224003322005087, 2003.

WAMDI group: The WAM model - a third generation ocean wave prediction model, J. Phys. Oceanogr., 18, 1775-1810, 1988.

Warner, J. C., Sherwood, C. R., Signell, R. P., Harris, C. K., and Arango, H. G.: Development of a three-dimensional, regional, coupled wave, current, and sediment-transport model, Comput. Geosci., 34, 1284-1306, doi:10.1016/j.cageo.2008.02.012, 2008.

Warner, J. C., Armstrong, B., He, R., and Zambon, J. B.: Development of a Coupled Ocean-Atmosphere-Wave-Sediment Transport (COAWST) Modeling System, Ocean Model., 35, 230-244, doi:10.1016/j.ocemod.2010.07.010, 2010. 
Webber, S. L., von Storch, H., Viterbo, P., and Zambresky, L.: Coupling an ocean wave model to an atmospheric general circulation model, Clim. Dynam., 9, 53-61, 1993.

Yelland, M. J., Moat, B. I., Taylor, P. K., Pascal, R. W., Hutchings, J., and Cornell, V: Wind stress measurements from the open ocean corrected for airflow distortion by the ship, J. Phys. Oceanogr., 28, 1511-1526, doi:10.1175/15200485(1998)028<1511:WSMFTO>2.0.CO;2, 1998.
Zambon, J. B., He, R., and Warner, J. C.: Investigation of hurricane Ivan using the coupled ocean-atmosphere-wave-sediment transport (COAWST) model, Ocean Dynam., 64, 1535-1554, doi:10.1007/s10236-014-0777-7, 2014.

Zhai, P. and Bower, A.: The response of the Red Sea to a strong wind jet near the Tokar Gap in summer, J. Geophys. Res.-Oceans, 118, 421-434, doi:10.1029/2012JC008444, 2013. 